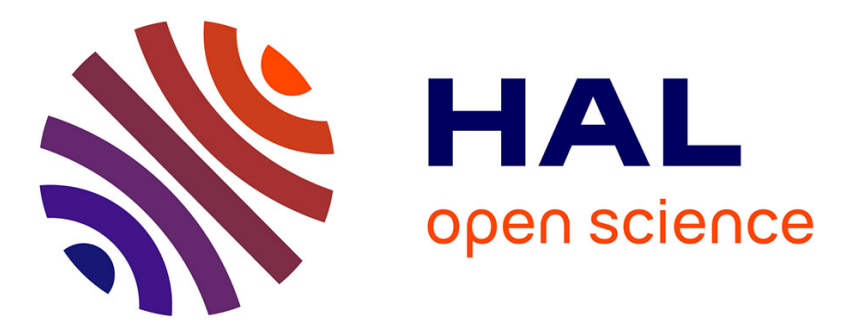

\title{
Mechanical characterisation of flax based woven fabrics and in situ measurements of tow tensile strain during the shape forming.
}

Pierre Ouagne, D. Soulat, C. Tephany, D. Duriatti, Samir Allaoui, G. Hivet

\section{- To cite this version:}

Pierre Ouagne, D. Soulat, C. Tephany, D. Duriatti, Samir Allaoui, et al.. Mechanical characterisation of flax based woven fabrics and in situ measurements of tow tensile strain during the shape forming.. Journal of Composite Materials, 2012, pp.1-15. hal-00772666

\section{HAL Id: hal-00772666 https://hal.science/hal-00772666}

Submitted on 10 Jan 2013

HAL is a multi-disciplinary open access archive for the deposit and dissemination of scientific research documents, whether they are published or not. The documents may come from teaching and research institutions in France or abroad, or from public or private research centers.
L'archive ouverte pluridisciplinaire HAL, est destinée au dépôt et à la diffusion de documents scientifiques de niveau recherche, publiés ou non, émanant des établissements d'enseignement et de recherche français ou étrangers, des laboratoires publics ou privés. 


\title{
Mechanical characterisation of flax based woven fabrics and in situ measurements of tow tensile strain during the shape forming.
}

\author{
P. Ouagne ${ }^{\mathrm{a} 1}$, D. Soulat ${ }^{\mathrm{b} 2}$, C. Tephany ${ }^{\mathrm{c} 1}$, D.Duriatti ${ }^{\mathrm{d} 3}, \mathrm{~S}$. Allaoui ${ }^{\mathrm{e} 1}$, G. $_{\text {. }}$ ivet $^{\mathrm{f1}}$
}

${ }^{1}$ Laboratoire PRISME, Université d'Orléans, 8 rue Léonard de Vinci 45072 Orléans, France.

${ }^{2}$ Gemtex, ENSAIT Roubaix 2, Allée Louise et Victor Champier, BP30329, 59056 Roubaix, France.

${ }^{3}$ Groupe Depestele - BP 21, 14540 Bourguebus - France

apierre.ouagne@univ-orleans.fr, ${ }^{b}$ damien.soulat@ensait.fr, ${ }^{\circ}$ christophe.tephany@etu.univorleans.fr, ${ }^{\mathrm{d}}$ dduriatti@depestele.com, ${ }^{\mathrm{e}}$ samir.allaoui@univ-orleans.fr, ${ }^{\dagger}$ gilles.hivet@univ-orleans.fr.

Keywords: Composites, natural fibres, flax fabric, sheet forming, In situ measurements, biaxial tension

\begin{abstract}
.
Forming complex shape composite parts with a good production rate/cost ratio is of particular importance for the automotive industry. The sheet forming of woven reinforcements is a promising technique especially if complex shapes with singularities such as case corners can be obtained. Due to the more and more important recycling needs, the use of flax fibre based reinforcements may be considered for structural or semi-structural parts. During the sheet forming of a tetrahedron shape, the tows constituting the architecture of the reinforcement material are submitted to tensile strains. When using glass or carbon fibre tows, strains to failure are generally not reached. When flax based fabrics are considered, the failure/degradation strength of the tows constituting the fabric may be reached. Even if no apparent failure is visible when observing the tows during forming, the strains measured by a mark tracking method indicate that the degradation limit of particular tows of the preform has been reached. This could lead to local lack of fibre density and to possible zones of weakness for the composite part. As a consequence, it is essential to improve the tensile performances of the tows constituting the fabric without losing their good impregnation characteristics and good ability to reach high mechanical properties for the composite part.
\end{abstract}




\section{Introduction}

Plant fibres, extensively explored as an environmentally friendly alternative to traditional glass fibre reinforcement, are characterised by lower density $\left(1.5 \mathrm{~g} / \mathrm{cm}^{3}\right.$ [1] for flax fibres) than glass fibres $\left(2.6 \mathrm{~g} / \mathrm{cm}^{3}\right)$. Moreover, they may be low cost and intrinsically biodegradable. Additional advantages of the use of natural fibres in composites are their renewability, biodegradability, non-toxicity, good insulation properties, low machine wear, etc [2-3]. Of course, the use of such fibres for the production of composite materials should be considered so that a constant quality of fibres is reached and in such a way that food production is not affected by their growth.

For the above positive reasons, a very large amount of work [1,4-7] has been devoted to analyze the tensile behaviour of individual fibres or group of few fibres of different nature and origin and has shown that the specific mechanical properties of natural fibres would be very comparable to those of glass fibres. This is particularly the case for the specific tensile modulus and strength of flax fibres. All these potentialities make natural fibres particularly suitable as glass fibre substitutes for applications in the automotive industry and this could lead, for the same part performance to an overall weight reduction of the composite [8].

All these studies, at the fibre scale, are justified by the fact that the natural fibres may show important variability in their mechanical properties. This is particularly the case when tensile strength and modulus are considered, because an apparent diameter is generally considered instead of a true cross-sectional area in the calculation of mechanical properties [9]. The mechanical properties of the fibres may also depend on the age of the plant, the geographical and climatic growth conditions, the harvesting method, the retting and the combing technique etc....[8], on the contrary of synthetic fibres. The variability of these mechanical properties, the compatibility between matrix and natural fibre and the moisture absorption [10] are the principal disadvantages which may prevent natural fibre composites from large-scale production [11]. As a consequence, review articles synthesise at the fibre scale the properties of the most widely considered natural fibres such as flax, hemp, jute, sisal, kenaf etc...[3, 12-14]. These review articles are particularly 
important as they enable to compare the properties of different fibres while considering the variability parameter.

An alternative way to avoid the consideration of the fibre properties variability is to characterise the material at the scale of the composite part made from natural fibres and polymeric resin [15-19]. The fibres generally in the form of reinforcement semi products (randomly arranged fibre mats, woven fabrics, non-crimped fabric, etc...) are mixed with polymeric resin during an impregnation process and composite samples may be extracted to perform mechanical tests. At this scale, a homogenised behaviour, depending on the used process and the used process parameters can be identified. Studies at the composite scale also enable to focus on the life cycle assessment of the part and on the complete energetic record linked to the use of the natural fibres [20-21]. Dissanayake et al. [22-23] analysed the energy used in the production of flax fibres for the reinforcement of composites. They showed, in the case of traditional production of flax mats, with the use of synthetic fertilizers and pesticides associated to traditional fibre extraction such as dew retting and hackling, that the energy consumption linked to the production of a flax mat is comparable to the energy consumed during the production of a glass mat. They also concluded that the spinning of fibres for the production of yarns typically used for the production of woven fabrics is an energy intensive operation. In that case, the glass woven fabric may appear superior to a flax woven fabric if one consider an environmental energy viewpoint. They also recommended designing new architectures of woven fabrics from aligned fibres tows, as it is the case for the reinforcement studied in this work, instead of spun yarn.

Between the two scales, (individual fibre, composite) few studies, according to our knowledge, deal with the mechanical behaviour of natural fibre assemblies such as strands, tows and dry reinforcement fabrics on the contrary to the numerous studies dealing with the subject for synthetic materials. Indeed, for structural application in the automotive or aeronautical industries numerous publications [24-27] study the mechanical characteristics and the deformability of carbon or glass 
reinforcements in conjunction to the manufacturing process. These studies concern the scale of tows, (fibre assemblies) and the scale of reinforcements (tow assemblies).

It has to be noticed that in the case of natural fibres, the fibre alignment technologies to elaborate tows from fibres, as well as the weaving technologies used to manufacture fabrics from tows are not described in the literature because each manufacturer uses its own parameters.

From aeronautical applications studies, generally for carbon/glass reinforcements, several publications $[24,25,28]$ show that during the manufacturing process the dry reinforcements may be subjected to complex deformation. This is particularly the case when complex forming is considered. As an example, the first step of the Resin Transfer Moulding (RTM) process [29] consists in forming dry reinforcements. During forming, tension, compression, shear, bending, ....deformations take place in the fabric. Deformations can also be coupled (tension and shear for example [25]).

These studies are carried out to anticipate the appearance of defects during the forming stage and to investigate the processability limits of a fabric especially when complex shapes linked to high mechanical resistance requirements are considered. It has to be noted that the preforming defects, as any modification of the deformation state, may modify the fabric permeability and as a consequence influence the impregnation stage [29-34] if one consider Liquid Composite Moulding (LCM) processes and particularly the RTM process. The preforming defect may also affect the quality of the final composite part [35-37]. Some of the preforming defects such as wrinkling, may be the result of limit behaviour in a given deformation mode. The limit behaviour for each considered deformation mode can be identified for a given reinforcement independently of the process by in plane tests such as uniaxial and biaxial tension, in plane shear test [24-26] and by out of plane tests such as flexure [27] or compaction [38-40]. As an example, the wrinkle defects are generally associated to an in-plane shear limit angle above which they appear. The shear behaviour can be determined using specific shear tests such as the bias or the picture frame tests $[25,26,41]$. 
Analysis of the strains taking place during the process may be evaluated in situ [41]. Up to now, the mechanical behaviours of the tows and fabrics have been mostly conducted on glass or carbon assemblies $[24,25,27]$. In this study, it is proposed to analyse the forming potentialities of a flax fibre based fabric, in the case of the sheet forming process associated to deformability studies at the scale of the tows and the fabric. This study particularly focuses on tension measurements taking place during the forming process on the contrary of the majority of the previous work that mostly deal with shear deformation. Indeed, the tows constituting the woven studied fabric are elaborated using fibres of limited length and therefore may be subject to partial failure at the origin of possible weaknesses in the composite part.

In this experimental study a sheet forming device associated to in situ stereo optical deformation measurement system is firstly briefly presented. This device originally developed in collaboration with EADS Company is particularly interesting because it enables for a given shape to determine and quantify the mechanical deformations taking place during the sheet forming process. Associated to the in situ measured strains, a specific device to analyse the tow or fabric behaviour in uni and bi-axial tension is presented. The results focussing on the tensile behaviour of tows during the forming process are then presented and put into relation to individual tension characterisation of tows in the fabric.

\section{Experimental procedures}

\subsection{Preforming device for dry reinforcement}

When using fabrics manufactured from untwisted tows to preform complex shapes, it is essential to investigate the presence of defects of any kind (fibre or tow damage, wrinkles, buckles, un-weaving ...etc) which may lead to a significant decrease of the composite performance, the good homogeneity of local fibre density and the state of deformation of the woven reinforcement because 
it modifies the permeability of the fabric and consequently the resin flow during the injection step [29-32].

A specific device was developed in collaboration with EADS Company (Figure 1.a) to investigate the sheet forming of textile reinforcements. It is composed of a punch/open-die couple which enables to obtain different double curvature shapes. The device is built so that any pair of punch/die can be adapted. The die is fixed and opened in order to measure and analyse the behaviour of the preform during the preforming stage [43]. The movement of the punch is conferred by an electric jack. In this study, a tetrahedron punch (Figure 1.b) was used.

To avoid wrinkling defects during the preforming tests it is possible to introduce tension in the tows by a classical multi-part blank holder. It is composed of independent blank holders actuated by pneumatic jacks that enable to impose and sensor independently a variable pressure. At the end of the preforming test, global analysis (dimensions, defects etc..) can be performed on the final state of the perform before removing it from the tool. The preform can be fixed by applying a spray of resin on its surface so that the preform can be removed from the tools and kept in its final state.

On complement and associated to these global information at the scale of the preform, it is important to measure local quantities such as the membranous positions, the orientations of the tows but also the 3D strains of the fabric. In this intention, the device is equipped by 3D Digital Image Correlation system which is a noncontact measurement method [44-46]. Two numerical cameras are located at the top of the device. They can be positioned as a function of the specific zone of the fabric that has to be analyzed. For the computation of the displacement field, marks tracking technique is used [47]. A speckle pattern needs to be applied on the fabric surface before the test by using white painting for dark fabrics and black painting for clear fabrics. A special care is given to this preparation because markers must be as circular as possible and their diameter lower than the width of the tows in order to avoid their deterioration during the test and thus disturb measurement [47]. The three space co-ordinates and thus the displacement field of these markers can be computed, using the marker tracking software Deftac 3D [48], from each digital image taken during 
the process and from the image captured at the reference state. With this $3 \mathrm{D}$ displacement field the membranous strains can be easily computed.

\subsection{Biaxial tension device}

A biaxial tension device associated to specific test samples (Figure 2) has also been used to characterise the tensile behaviour of the considered flax fabric. Particularly, non-linearity of the load deformation curve due to $2 \mathrm{D}$ assembly of the woven reinforcement should be investigated as well as the tensile limit behaviour of the fabric using this device. The tensile strains for each considered tows are measured using a $2 \mathrm{D}$ version of the mark tracking device described in the previous section. It has to be noted that this device can also be used to perform uniaxial test as well as mechanical tests on individual tows. The detailed description of the device as well as the procedure of the test may be found in [49].

\subsection{Tested material}

The flax fabric (Figure 3.a) used in this study, is a plain weave fabric with an areal weight of $280 \pm 19 \mathrm{~g} / \mathrm{m}^{2}$, manufactured by Groupe Depestele (France). The fabric is not balanced, as the space between the weft tows $(1.59 \pm 0.09 \mathrm{~mm})$ is different to the one between the warp tows $(0.26 \pm 0.03$ $\mathrm{mm})$. The width of the warp and the weft tows are respectively $2.53 \pm 0.12 \mathrm{~mm}$ and $3.25 \pm 0.04 \mathrm{~mm}$. As a consequence, there are 360 warp tows and 206 weft tows per metre of fabric. The linear mass of the warp and the weft tows is the same and is equal to $494 \pm 17 \mathrm{~g} / \mathrm{km}$. The tows are constituted by globally aligned groups of fibres. The length of these groups of fibres varies between 40 to $600 \mathrm{~mm}$ with a maximum occurrence taking place at $80 \mathrm{~mm}$.

This fabric is constituted of continuous rectangular untwisted tows (Figure 3.b) to avoid the presence of vacancies close to the crimp areas and to favour its impregnability. This reinforcement was originally developed to manufacture large panels with low curvature and was therefore not optimised for complex shape forming. 


\section{Results}

\subsection{Global preform analysis}

In previous studies dealing with the subject of fabric forming, spherical and hemispherical preforms were particularly studied because the shape is rather simple, it is doubled curved and because it leads to large shear angles between the tows [50-52]. To analyse the feasibility and the deformability in severe cases such as the ones taking place in real semi structural automotive parts, a tetrahedron punch with very small radiuses of curvature is chosen to investigate the possibility of using sheet forming to generate geometries possessing for examples triple curvature points. The maximum depth of the punch is $160 \mathrm{~mm}$. For the test, an initial square specimen of the flax fabric is positioned with six blank holders placed specifically around the tetrahedron punch. On each of them a pressure of two bars $(200 \mathrm{kPa})$ is applied.

A first global analysis at the preform scale can be conducted. It shows that the global tetrahedron shape is obtained. It also shows that wrinkle, vacancy or torn fabric defects are not observed in the useful zone. Out of the useful zone, some wrinkles can be observed (Figure 4.a) around the preform, and around the blank holders.

More locally, some material over-thickness zones take place in the middle of certain faces (Figure 4.b) and on some edges of the formed tetrahedron shape. Those over-thicknesses are the consequence of buckles generated by some tows perpendicular to the one passing by the top of the tetrahedron shape. This buckling phenomenon cannot be acceptable in terms of preform quality as the homogeneity of the thickness preform is not controlled. This specific defect is not observed for all shapes but has already been encountered [53, 54]. It depends on the shape of the required preform and on the constitution of the tows and the architecture of the fabric. This specific subject will be treated in another study.

\subsection{Tensile strain measurements during forming of the tetrahedron shape}

Visually, some tows on the preform seem to be very tight. This is particularly the case of the vertical tows passing by the triple point (top of the tetrahedron). A local analysis of the tensile 
strains using a mark tracking method is carried out on those tows to quantify the values of deformation reached. Results are extracted from measurements carried out on Face C (Figure 5).

Figure 6 shows the position of the tested tows and the place between which the strain was measured (between the round dots on the coloured lines). Figure 7 shows the values of the strains measured on the four considered tows for one face of the tetrahedron shape in the case of weft vertical tows (denoted orientation $0^{\circ}$ ). The results show that the strain rises in a non uniform way during the sheet forming process. At the beginning of the test, no strain is observed as the punch is not in contact with the fabric. Once in contact, the strain in the different tows rises in a regular manner up to values above which the strain increases with a lower slope. At the end of the higher slope, the tows are submitted to strong tension loads and it is expected that this activates the movement of the ply between the blank holders. From that time, the rise of the punch and therefore of the reinforcement is accommodated by the deformation of the tows (increasing distance between marks), but also by a global movement of the fabric between the blank holders. If a second mechanism takes place to enable the fabric to follow the punch displacement, it seems normal that the tensile strain slope decreases. In the case of Figure 7, it is expected that the movement of the fabric between the blank holder starts for a punch displacement of about $35 \mathrm{~mm}$.

Figure 7 also shows that the strains measured on the tows passing by or close to the triple point (top of the tetrahedron) are higher than the other ones. The tensile strain decreases as a function of the increasing distance from the triple point.

As the fabric used in this study is not balanced, local strain measurements have also been carried out in the case of $90^{\circ}$ orientation (with the warp tows being vertical on the face) with the same process parameters (similar punch displacement and blank holder pressure). Figure 8 shows the evolution of the tensile strains of the tow passing by the triple point as well as the one of the sixth tow on the right of the face for the two orientations. For the tow passing by the triple point and for the sixth tow on the right, the tensile strains are much lower for the $90^{\circ}$ orientation than for the $0^{\circ}$ one and this for the same process conditions. This is probably due to the fact that the fabric is 
unbalanced. The warp tows are placed very close to each other whereas a space can be observed between the weft tows. As a consequence, the warp tows encounter less perpendicular tows in a given distance (the one of a test sample for example) than the weft tows for the same distance. The warp tows in this woven fabric are therefore stiffer than the weft ones. This is due to the crimp effect which is more important for the weft tows. These tests show that the behaviour of the considered woven fabric during the preforming process is a biaxial phenomenon.

Figure 7 shows that the strain measured on vertical tows passing close to the triple point are higher than for the strain measured on the other ones. The triple point tow is therefore tighter than the neighbouring ones. Because the flax tow is constituted from finite length fibre assemblies (as discussed in section 2.3), the local tow resistance may not be uniform as in the case of carbon or glass tows. As a consequence, it may be of interest to investigate locally (between chosen mark points) the tensile strain along a single tow (Figure 9). Figure 10 shows that the strain is not uniform along the length of the investigated tow. For measurements carried out close to the top of the preform, a higher strain is recorded. The tensile strain then decreases when the measurement is carried out on lower parts of the tow. This confirms that the tensile strain is not uniform even for a given tow along its length, suggesting that internal fibre movement and frictions between the weft and the warp tows may take place differentially along the tow length.

The influence of the blank holder pressure has also been investigated. Figure 11 shows that the tensile strain increases as a function of the blank holder pressure suggesting that more movement between the fibres takes place within the tows when the blank holder pressure increases. If one supposes that the large deformation recorded on the tows especially for the ones close to the triple point is associated to movements of fibres within the tows, this could lead locally to a lack of fibre density and to zones of weakness for the composite part even if no failure has been observed macroscopically.

All the previous observations (Figures 8,10,11) show that tensile strain raises in tows when measurements are carried out closer and closer to the triple point and when the blank holder 
pressure increases. The observations also indicate that the tensile strains depend on the orientation of the fabric as this one is unbalanced. The high recorded strains may indicate that movement of fibres and possibly inhomogeneous fibre density within the tow takes place during the biaxial loading of the fabric. It would therefore be interesting to characterise the biaxial behaviour of the fabric independently of the process to determine for example the strain at which the fibre movements and the possible loss of fibre density are expected to take place.

\subsection{Characterisation of the Fabric tensile behaviour 3.3.1 Uniaxial tests}

It is proposed in this part to study the behaviour of warp and weft tows through uniaxial and biaxial tensile test of the fabric. The crimp effect due to the interlacing of the tows is taken into account. Moreover, the tensile state of the tows perpendicular to the ones to characterise is of importance as these ones influence their behaviour by pinching effect at the interlacing places. As biaxial deformations of the fabric is supposed to take place during the sheet forming of the tetrahedron shape, a single uniaxial test is not sufficient to characterise the tensile behaviour of the fabric, and a set of biaxial test, by varying the deformation rate in the perpendicular direction, needs to be carried out in both directions as the fabric is not balanced.

Figure 12 shows uniaxial tensile test specimen. In this case, a tensile load is applied on the weft tows as labelled in Figure 12. Figure 13 presents the uniaxial tension behaviour of the individual weft tows of the tested piece of fabric. At low strain, a non linearity zone is observed. Then, the load rises quickly in a linear way up to the maximum load the tow can sustain. For higher deformation, the load decreases. It can be noted that the dispersion of the results is low as the curves in Figures 13 are almost superimposed. Figure 13 also illustrates the fact that the tows perpendicular to the investigated ones are submitted to compression loads because of the weaving effect.

The strain values corresponding to the loss of tow stiffness are presented in Table 1 For the weft tows this value is $4.5 \pm 0.2 \%$. Table 1 indicates that the value at which the load decreases does not show an important dispersion (4.2\%). 
Table 1 and Figure 14 show the result of uniaxial tension test performed in the warp direction. The results indicate that the strain at the maximum load is much lower than in the case of the weft tows. This value for the warp tow is $1.4 \pm 0.2 \%$. This is due to the crimp effect already mentioned when measuring the tensile strain during the process. This one is more important for the weft tows than for the warp tows.

\subsubsection{Biaxial tests}

Biaxial tests were carried out to study the tensile behaviour of the flax fabric. The results showing the biaxial behaviour of the fabric in the weft direction are presented in Figure 15 for different values of the parameter $k t$. The parameter $k t=\varepsilon_{w e} / \varepsilon_{w a}$ is defined as the ratio between the strain in the weft direction $\left(\varepsilon_{w e}\right)$ over the one in the warp direction $\left(\varepsilon_{w a}\right)$. The results show that an increasing value of $k t$ leads to higher "failure/limiting" strain in the weft tows. This means that the crimp effect decreases in this case. The crimp effect is the lowest when the warp direction is not loaded and therefore left free. As the warp tows are left free, these ones are not tight and therefore the crimp effect and the associated non linearity zone is more pronounced.

Figure 16 shows the influence of the weft tow deformation upon the warp tow behaviour. When the strain in the weft direction increases, the tension in the warp direction also increases for a same warp strain. As a consequence, when $k t$ rises the tension in the warp tows increases more quickly. As mentioned in Section 3.3.1 for the uniaxial tests, the strains at the maximum loads are also higher for the weft tows than for the warp tows. The same crimp effect is responsible for this observation.

The strain values observed at the maximum load point during a biaxial test are lower than in the case of the uniaxial test performed with same dimension samples and this for the two directions. As a consequence, the strains at which the load is maximum are lower than $4.5 \%$ in the weft direction and $1.4 \%$ in the warp direction during the uniaxial test. As already mentioned, these strain values represent the limit from which a loss of fibre density takes place in the tows and this phenomenon 
should probably be avoided by keeping the tensile strain in the tetrahedron preform lower than these values.

\section{Discussions}

The studied woven flax fabric is composed of untwisted tows as this favours its impregnation and the mechanical properties of the final composite [55]. However, the tensile resistance of the tow elaborated from finite length fibres depends on the degree of entanglement of the fibres. The failure resistance of the tows constituting the studied flax fabric has been evaluated through a series of uniaxial and biaxial tests of the fabric in the direction of the warp and the weft tows. No brutal and visible failure of the tow is observed during the mechanical tensile tests. However, above a defined strain, the tows lose their stiffness and local fibre density losses could take place. As the load necessary to reach this point is relatively low, in-situ investigations of the tensile strains have been carried out. It was showed that the tensile strains are not uniform on the face of the fabric and also along the tow itself. The in-situ tensile measurements on the face of the tetrahedron shape showed that the tows submitted to the higher loads (the ones passing by the triple point of the shape) exhibit strains $(\approx 9.5 \%)$ higher than the point at which the tows lose a part of their stiffness $(\approx 4 \%)$ for orientation $0^{\circ}$ weft tows. In this case, it is probable that local failure, characterised by movement of fibres or groups of fibres, are at the origin of local losses of fibre density. Even if it would probably be better to avoid such fibre density losses, it would be interesting to quantify it and to evaluate its impact on the mechanical property of the final composite part.

In any case, it would be interesting to manufacture tows with higher tensile resistance in order to avoid local lack of fibre density without using twisted yarns. It may be interesting for example to design tows with slightly entangled fibres to provide them enough resistance to sustain the loads involved during complex shape forming. 
Uniaxial and biaxial tensile behaviours of the studied flax-based woven fabric can also be used as input data for the sheet forming simulation codes [56-58] which could be used in an iterative loop to design and optimise the architecture of new reinforcement material that could be used to form complex shape without defects.

\section{Conclusions}

The methodology to identify, characterize and model the mechanical behaviour of synthetic glass or carbon fibre reinforcements has been the subject of numerous studies at the different scales of interest (fibre, tow, fabric). For natural fibre based reinforcements, most of the studies are limited to the scale of the fibre. This study shows that the global behaviour of the flax fibre based woven fabric is related to the multi-scale nature of the reinforcement. The work presented in this study investigates the scale of the tow and the scale of the fabric associated to the complex sheet forming of a flax plain weave fabric. The architecture of the woven fabric (the way the tows are arranged in the fabric structure) provides the ability of the reinforcement to be deformed by the in-plane shear mechanism. The global tetrahedron shape has been obtained without any wrinkles at the membrane scale. During the sheet forming of the fabric into a complex tetrahedron shape, the tows (an assembly of aligned fibres of limited length) are submitted to tensile loads. Even if no apparent failure is visible when observing the tows, the strain of the tightest tows of the preform has been measured and compared to the uniaxial and biaxial strains of the fabric determined independently of the process by specific tests. The results show that the strains in the tows close to the triple point of the shape (top of the tetrahedron) are higher than the strain above which local failure, determined by uniaxial and biaxial tension tests, is expected to take place. This could lead to local lack of fibre density and to possible zones of weakness for the composite part. It would therefore be interesting to improve the tensile performances of the tows constituting the fabric without losing their good impregnation characteristics and good ability to reach high mechanical properties for the composite 
part. Improving the tensile performances of the tows constituting the flax based woven fabrics should be conducted in the scope of wider studies consisting in optimising (using both experimental and simulation tools) the constitution and the architecture of the reinforcement at the scale of the tow and the fabric.

\section{References}

1. Baley C. "Analysis of the flax fibres tensile behaviour and analysis of the tensile increase". Composites: Part A, 33 (2002), 2143-2145.

2. Ku H., Wang H., Pattarachaiyakoop N., Trada M. "A review on the tensile properties of natural fiber reinforced composites" Composites: Part B, 42 (2011), 856-873.

3. Dittenber, D.B., Ganga Rao H.V.S., "Critical Review of Recent Publications on Use of Natural Composites in Infrastructure“. Composites: Part A, 43 (2012), 1419-1429.

4. Charlet K., Jernot J.P., Eve S., Gomina M., Breard J. "Multi-scale morphological characterisation of flax: From the stem to the fibrils". Carbohydrate Polymers, 82 (2010) 54-61.

5. Bodros E., Baley C. "Study of the tensile properties of stinging nettle fibres". Materials Letter, 62 (2008), 2143-2145.

6. Pillin I., Kervoelen A., Bourmaud A., Goimard J., Montrelay N., Baley C. "Could oleaginous flax fibers be used as reinforcement for polymers?" Industrial Crops and Products, 34 (2011) $1556-1563$.

7. Ochi S. "Mechanical properties of kenaf fibers and kenaf/PLA composites". Mechanics of Materials, 40 (2008) 446-452.

8. Zini E., Scandola M.. “Green Composites: An Overview”. Polymer composites (2011) 19051915.

9. Virk A.S., Hall W., Summerscales J. Failure strain as the key design criterion for fracture of natural fibre composites Composites Science and Technology, 70 (2010) 995-999.

10. Stamboulis A., Baillie C., Peijs T. "Effects of environmental conditions on mechanical and physical properties of flax fibers". Composites: Part A, 32 (2001), 1105-1115.

11. Peng X., Fan M., Hartley J., Al-Zubaidy. "Properties of natural fiber composites made by pultrusion" Journal of Composite Materials, 46 (2012), 237-246.

12. La Mantia F.P., Morreale M. "Green composites: A brief review." Composites: Part A, 42 (2011), 579-588.

13. Biagiotti J., Puglia D., Kenny J.M.. "A Review on Natural Fibre-Based Composites-Part I" Journal of Natural Fibers, 1:2, (2004) 37-68.

14. Puglia, D. , Biagiotti, J., Kenny, J.M. “A Review on Natural Fibre-Based Composites-Part II“. Journal of Natural Fibers, 1: 3 (2005), 23 - 65.

15. Summerscales J., Dissanayake N., Virk A., Hall W. "A review of bast fibres and their composites. Part 2 Composite". Composites: Part A, 41 (2010) 1336-1344.

16. Satyanarayana K. G., Arizaga G. G.C., Wypych F. "Biodegradable composites based on lignocellulosic fibers-An overview” Progress in Polymer Science, 34 (2009), 982-1021. 
17. Pandey J. K., Ahn S. H., Lee C. S., Mohanty A. K., Misra M. "Recent Advances in the Application of Natural Fiber Based Composites". Macromolecular Materials and Engineering, 295 (2010), 975-989.

18. Ouagne P., Bizet L., Baley C., Bréard J. "Analysis of the Film-stacking Processing Parameters for PLLA/Flax Fiber Biocomposites”. Journal of Composite Materials, 44 (2010), 1201-1215.

19. Alawar A., Hamed A.M., Al-Kaabi K. "Characterization of treated data palm tree fiber as composite reinforcement". Composites: Part B, 40 (2009), 601-606.

20. Le Duigou A., Davies P., Baley C. "Environmental Impact Analysis of the Production of Flax Fibres to be Used as Composite Material Reinforcement". Journal of Biobased Materials and Bioenergy, 5 (2011) 153-165.

21. Kim S., Dale B., E. Drzal, LT., Misra M. "Life Cycle Assessment of Kenaf Fiber Reinforced Biocomposite". Journal of Biobased Materials and Bioenergy, 2 (2008) 85-93.

22. Dissanayake, N.; Summerscales, J.; Grove, S.; Singh, M. "Life Cycle Impact Assessment of Flax Fibre for the Reinforcement of Composites" Journal of Biobased Materials and Bioenergy, 3 (2009), 245-248.

23. Dissanayake, N.; Summerscales, J.; Grove, S.; Singh, M. "Energy use in the production flax fiber for the reinforcement of composites" Journal of Natural Fibers, (2009), 331-346.

24. Buet-Gautier K, Boisse P. "Experimental analysis and modelling of biaxial mechanical behaviour of woven composite reinforcements." Experimental Mechanics, 41 (2001); (3):260-9.

25. Launay J., Hivet G. Duong A.V., Boisse P. "Experimental analysis of the influence of tensions on in plane shear behaviour of woven composites reinforcements". Composite Science and Technology, 68 (2008) 506-515.

26. Cao J. et al. "Characterization of mechanical behavior of woven fabrics: Experimental methods and benchmark results". Composites: Part A, 39 (2008) 1037-1053.

27. De Bilbao E., Soulat D., Hivet G., Gasser A. "Experimental study of bending behaviour of reinforcements" Experimental Mechanics, 50, (3) (2010) 333-351

28. Allaoui S., Boisse P., Chatel S., Hamila N., Hivet G., Soulat D., Vidal-Salle E. "Experimental and numerical analyses of textile reinforcement forming of a tetrahedral shape". Composites: Part A, 42 (2011) 612-622.

29. Rudd CD, Long AC. Liquid molding technologies. Woodhead Publishing Limited; 1997.

30. Arbter, R., Beraud, J.M., Binetruy, C., Bizet, L., Bréard, J., Comas-Cardona, S., Demaria, C., Endruweit, A., Ermanni, P., Gommer, F., Hasanovic, S., Henrat, P., Klunker, F., Laine, B., Lavanchy, S., Lomov, S.V., Long, A., Michaud, V., Morren, G., Ruiz, E., Sol, H., Trochu, F., Verleye, B., Wietgrefe, M., Wu, W., Ziegmann, G., "Experimental Determination of the Permeability of Textiles: A Benchmark Exercise". Composites: Part A, 42 (2011) 1157-1168.

31. Van Den Broucke B., Hamila N., Middendorf P., V. Lomov S., Boisse P., Verpoest I. "Determination of the mechanical properties of textile-reinforced composites taking into account textile forming parameters". International Journal of Material Forming, 3 (2010); 1351-1361.

32. Heardmann E., Lekakou C., Bader M.G. "In plane permeability of sheared fabrics". Composites: Part A., 32 (2001) 933-940.

33. Long A.C., "Process modeling for liquid moulding of braided preform." Composites: Part A, 32 (2001) 941-953.

34. Ouagne P., Bréard J. "Continuous transverse permeability of fibrous media." Composites: Part A, 41 (2010) 22-28.

35. Prodromou AG, Chen J. "On the relationship between shear angle and wrinkling of textile composite preforms“. Composite:s Part ,. 28 (1997) 491-503. 
36. Lomov S.V., Boisse Ph., Deluycker E., Morestin F., Vanclooster K., Vandepitte D., Verpoest I., Willems A.. "Full-field strain measurements in textile deformability studies". Composites: PartA, 39 (2008) 1218-1231.

37. Skordos A.A., Aceves C.M., Sutcliffe M.P.F. "A simplified rate dependent model of forming and wrinkling of pre-impregnated woven composites." Composites: Part A, 38 (2007) 13181330.

38. Robitaille F, Gauvin R. "Compaction of textile reinforcements for composites manufacturing. I: Review of experimental results". Polymer Composites, 19 (1998) 198-216.

39. Kelly PA, Umer R, Bickerton S. "Viscoelastic response of dry and wet fibrous materials during infusion processes." Composites: Part A 37 (2006) 868-873.

40. Ouagne P, Bréard J, Ouahbi T, Saouab A, and Park C-H. "Hydro-Mechanical Loading and Compressibility of Fibrous Media for Resin Infusion Processes". International Journal of Materials Forming, 3 (2010) 1287- 1294.

41. Hivet G., Duong AV. "A contribution to the analysis of the intrinsic shear behaviour of fabrics". Journal of Composite Materials, 45 (2011) 695-717.

42. Soulat D., Allaoui S., Chatel S. "Experimental device for the optimization step of the RTM process".International Journal of Materials Forming, 2 (2009) 181-184.

43. Allaoui S., Launay J., Soulat D., Chatel S. "Experimental tool of woven reinforcement forming". International Journal of Materials Forming, 2 (2008) 815-818.

44. Dumont F., Hivet G., Rotinat R., Launay J., Boisse P., Vacher P. "Field measurements for shear tests on woven reinforcements". Mecanique et Industrie. 4 (2003) 627-635.(in French)

45. Willems A, Lomov SV, Verpoest I, Vandepitte D. "Optical strain fields in shear and tensile testing of textile reinforcements". Composite Science and Technology, 68 (2008) 807-819.

46. Launay J., Lahmar F., Boisse P., Vacher P. "Strain measurement in tests of fibre fabric by image correlation method“. Advanced Composites Letters, 11 (2002) 7-12.

47. Bretagne N., Valle V., Dupré JC. "Development of the marks traking technique for strain field and volume variation measurements“. NDT\&E International, 38 (2005) 290-298.

48. Bremand, F., Dupre, J.C., Lagarde, A. "Mesure de déformations sans contact par analyse d'images“. In proceedings of Photomechanics. (1995): 171-177.

49. Boisse P., Gasser A., Hivet G. "Analyses of fabric tensile behaviour : determination of the biaxial tension-strain surfaces and their use in forming simulation". Composites: Part A, 32 (2001): 1395-1414.

50. Molnar P., Ogale A., Lahr R., Mitschang P. "Influence of drapability by using thermoforming" Composites Science and Technology, 67 (2007), 3386-3393.

51. Li X., Bai S. "Sheet forming of the multy-layered biaxial weft knitted fabric reinforcement. Part 1: On hemispherical surfaces" Composites: Part A, 40 (2009), 766-777.

52. Vanclooster K., Lomov S.V., Verpoest I. "Experimental validation of forming simulations on fabric reinforced polymers using an unsymmetrical mould configuration. Composites: Part A, 40 (2009), 530-539.

53. Ouagne P., Soulat D., Hivet G., Allaoui S., Duriatti D. "Analysis of defects during the preforming of a woven flax reinforcement". Advanced Composite Letters, 20 (2011) 105-108.

54. Lee J., Hong S., Yu W., Kang T. "The effect of blank holder force on the stamp forming behavior of non-crimp fabric with a chain stitch". Composite Science and Technology, 67 (2007), (3-4):357-366.

55. Goutianos S., Peijs T., Nystrom B. Skrifvars M. "Development of flax based textile reinforcements for composite applications" Applied Composites Materials, 13 (2006), 199-215.

56. Boisse P, Hamila N, Vidal-Sallé E, Dumont F. "Simulation of wrinkling during textile composite reinforcement forming, Influence of tensile, in-plane shear and bending stiffnesses." Composite Science and Technology,71 (2011) 683-92.

57. Peng X., Rehman Z. "Textile composite double dome stamping simulation using a nonorthogonal constitutive model." Composite Science and Technology,71 (2011) 1075-1081. 
58. Peng X., Ding F. "Validation of a non-orthogonal constitutive model for woven composite fabrics via hemispherical stamping simulation”. Composites: Part A, 42 (2011) 400-407. 


\section{Acknowledgements}

The authors would like to thank the "ADEME" (Agence de l'environnement et de la Maitrise de l'Energie) and "Region Centre" for financial support. 


\begin{tabular}{|c|c|c|c|}
\cline { 2 - 4 } \multicolumn{1}{c|}{} & Mean value & $\begin{array}{c}\text { Standard } \\
\text { deviation }\end{array}$ & $\begin{array}{c}\text { Standard } \\
\text { deviation/mean value \% }\end{array}$ \\
\hline $\begin{array}{c}\text { Strain in weft } \\
\text { direction at } \\
\text { maximum load }\end{array}$ & 0.045 & 0.002 & 4.2 \\
\hline $\begin{array}{c}\text { Strain in warp } \\
\text { direction at } \\
\text { maximum load }\end{array}$ & 0.014 & 0.002 & 6.1 \\
\hline
\end{tabular}

Table 1: Average maximum strain, uniaxial tension. 
(a)

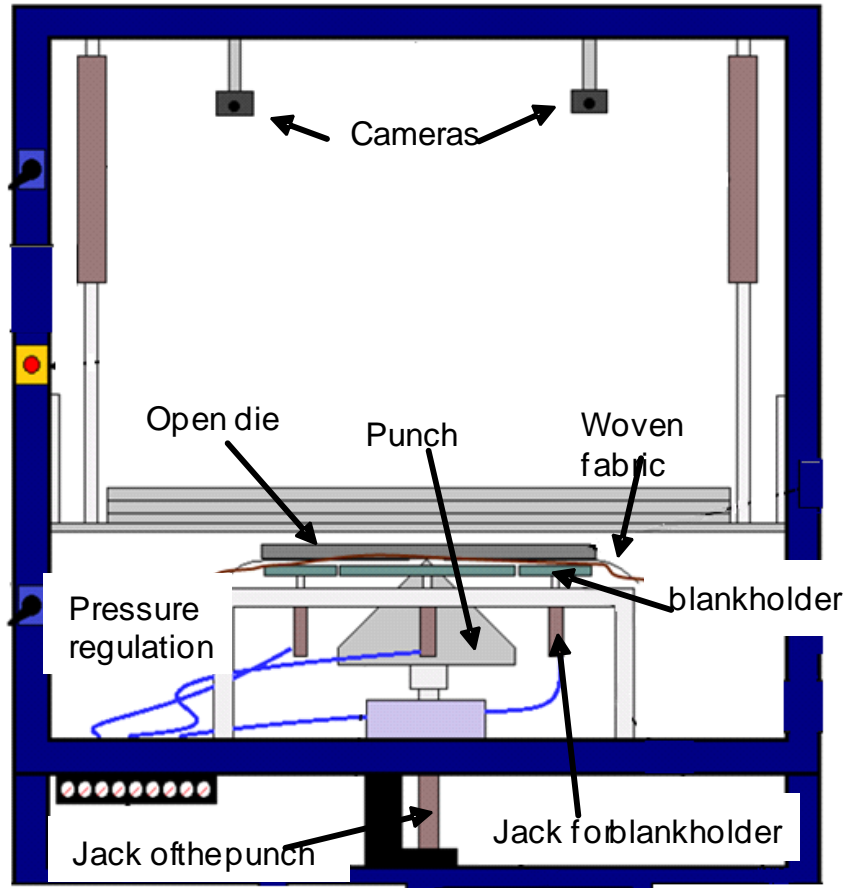

(b)

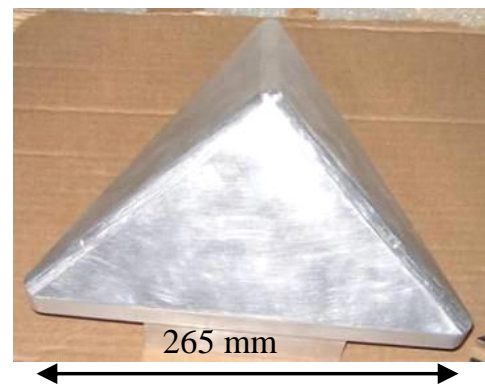

Figure 1: (a) Description of the device. (b) Tetrahedron punch.

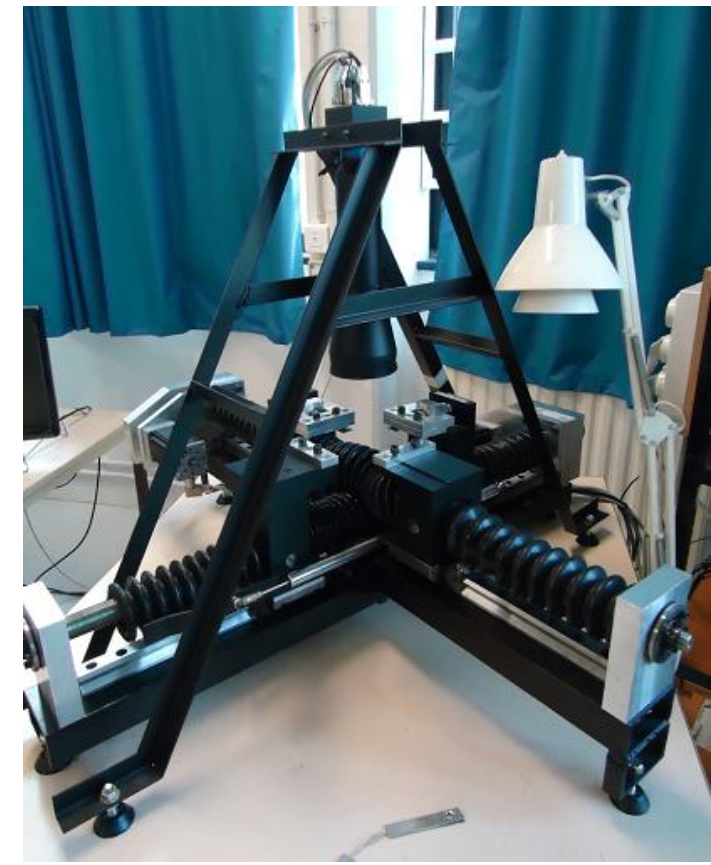

(a)

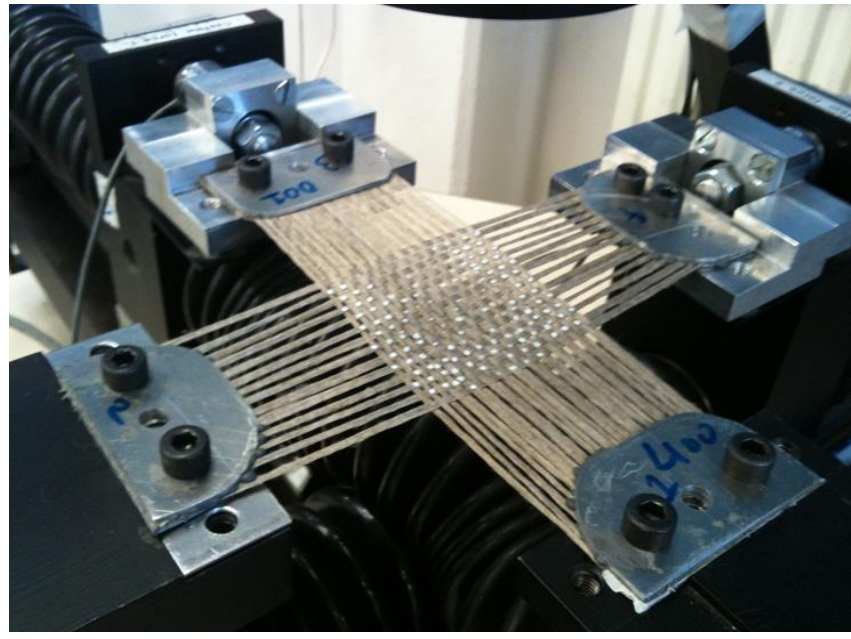

(b)

Figure 2: (a) The biaxial tension device. (b) Biaxial tension test sample 


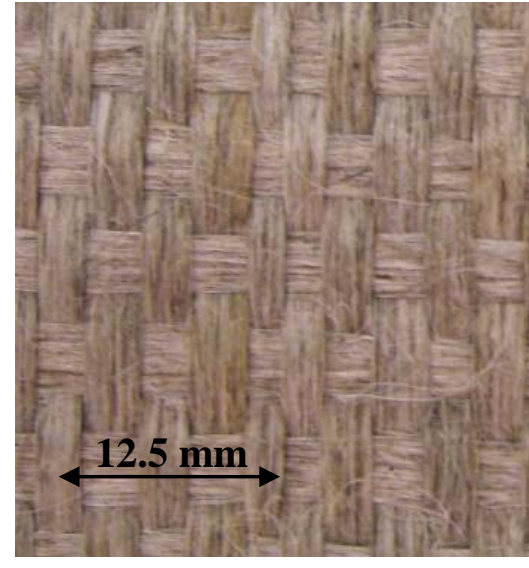

(a)

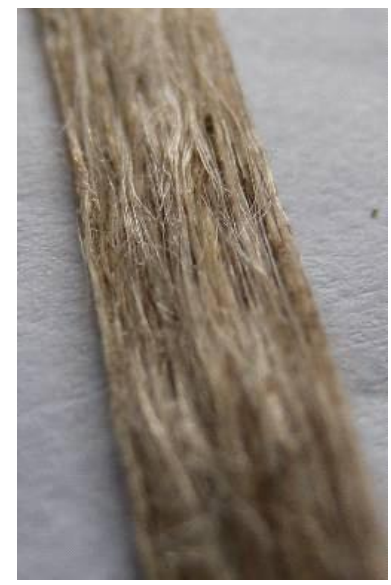

(b)

Figure 3: (a) Flax fabric (b) Flax tow

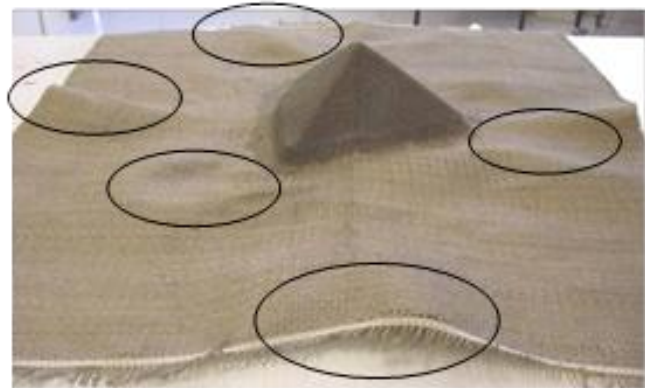

(a)

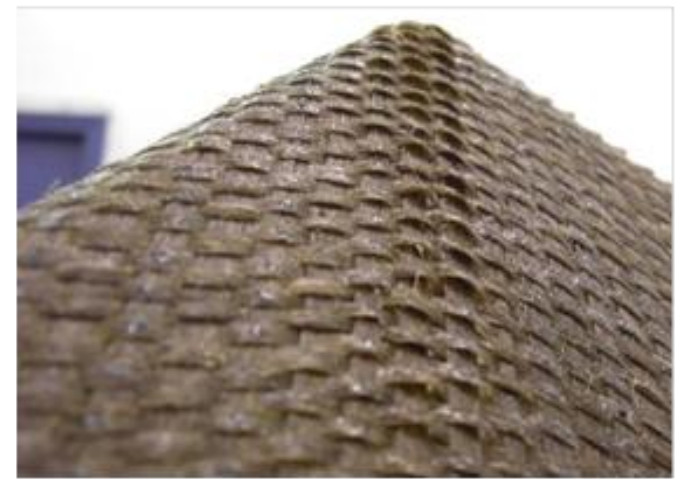

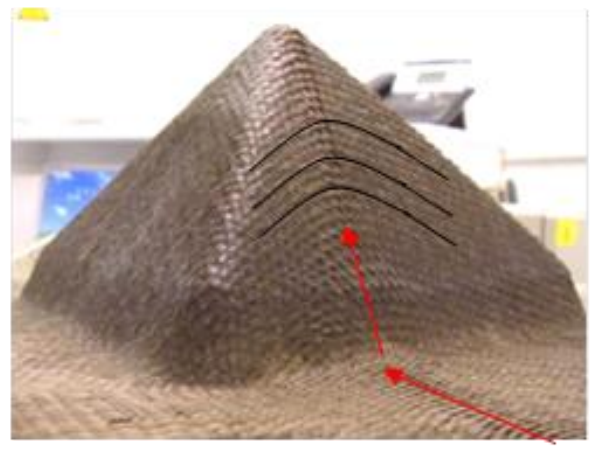

(b)

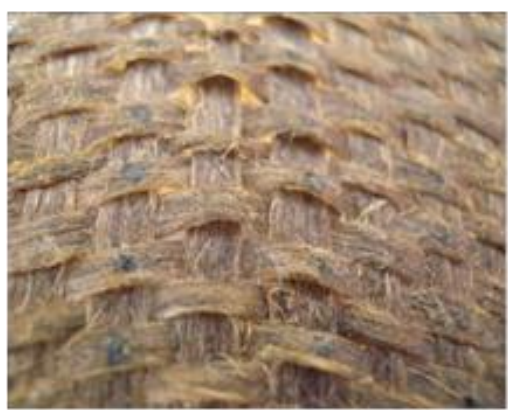

(c)

Figure 4: (a) Wrinkles outside of the useful zone; (b) Position of the buckles ;

(c) Focus on the buckles 


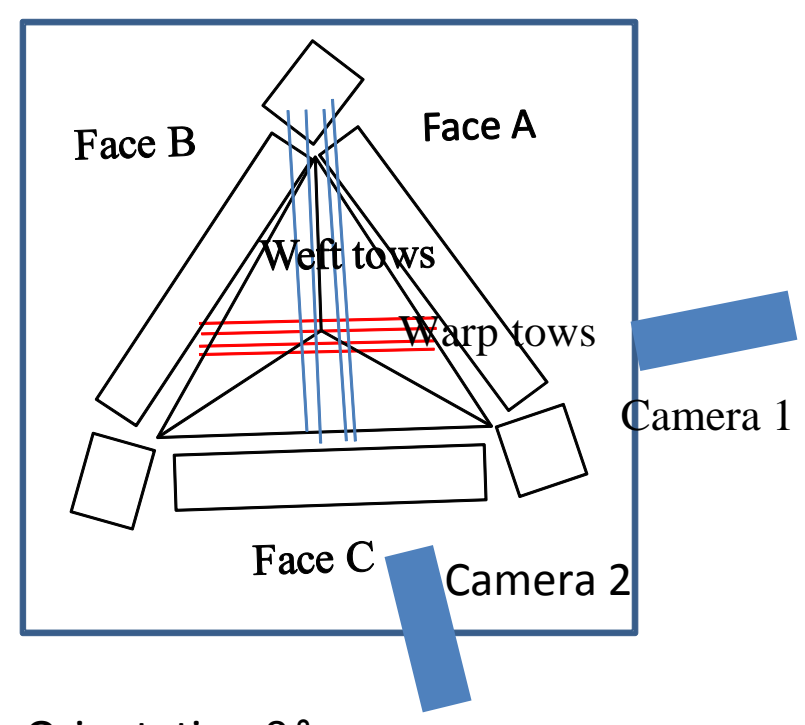

Orientation $0^{\circ}$ :

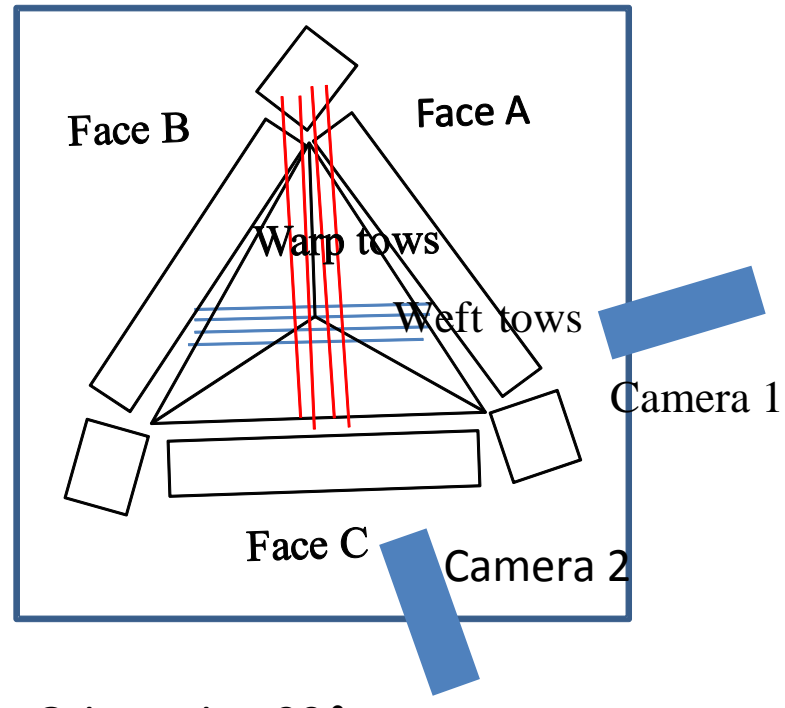

Orientation $90^{\circ}:$

Figure 5: Orientation of the fabric on the forming device

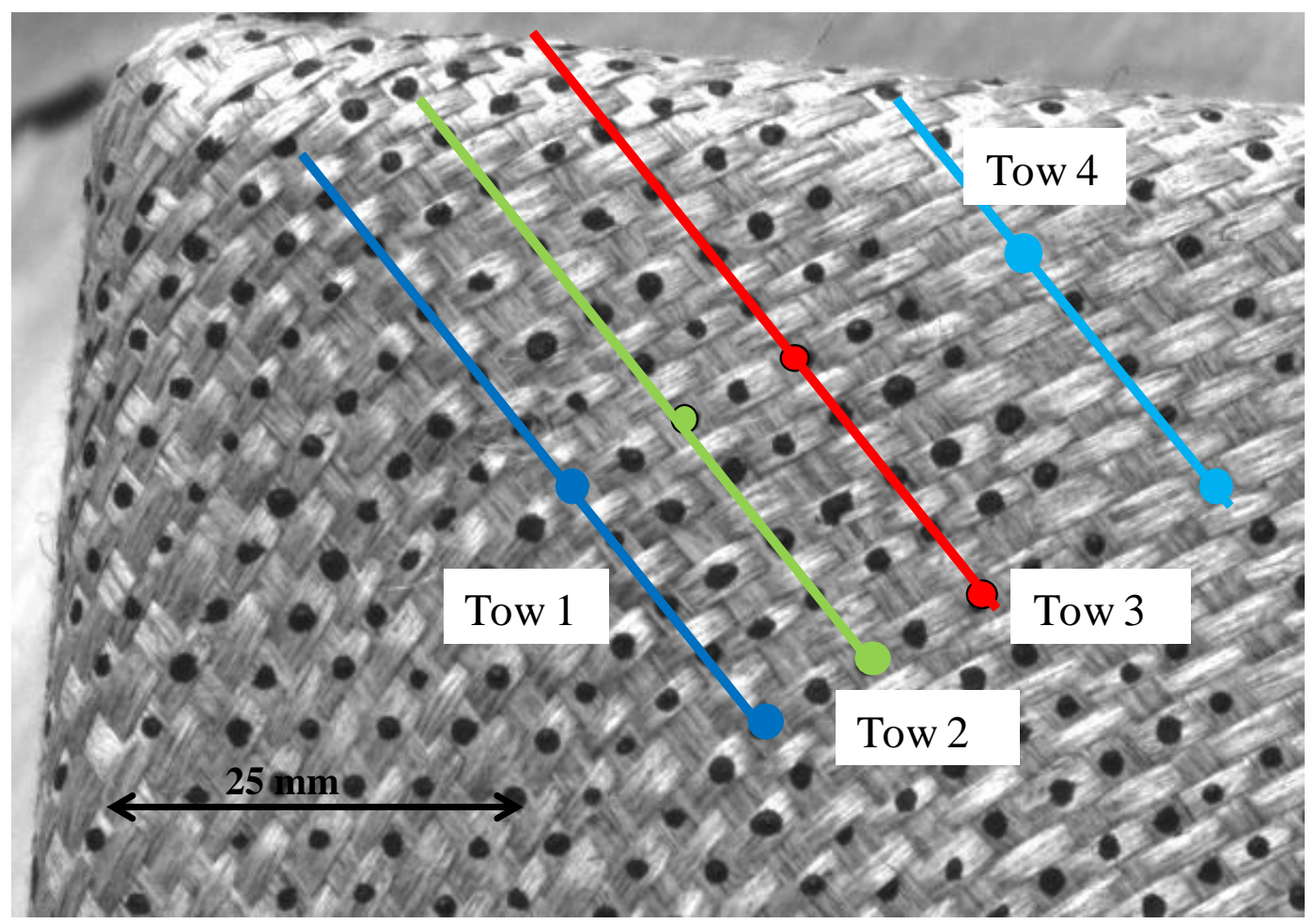

Figure 6: Position of the tows and position of the marks used for strain measurement 


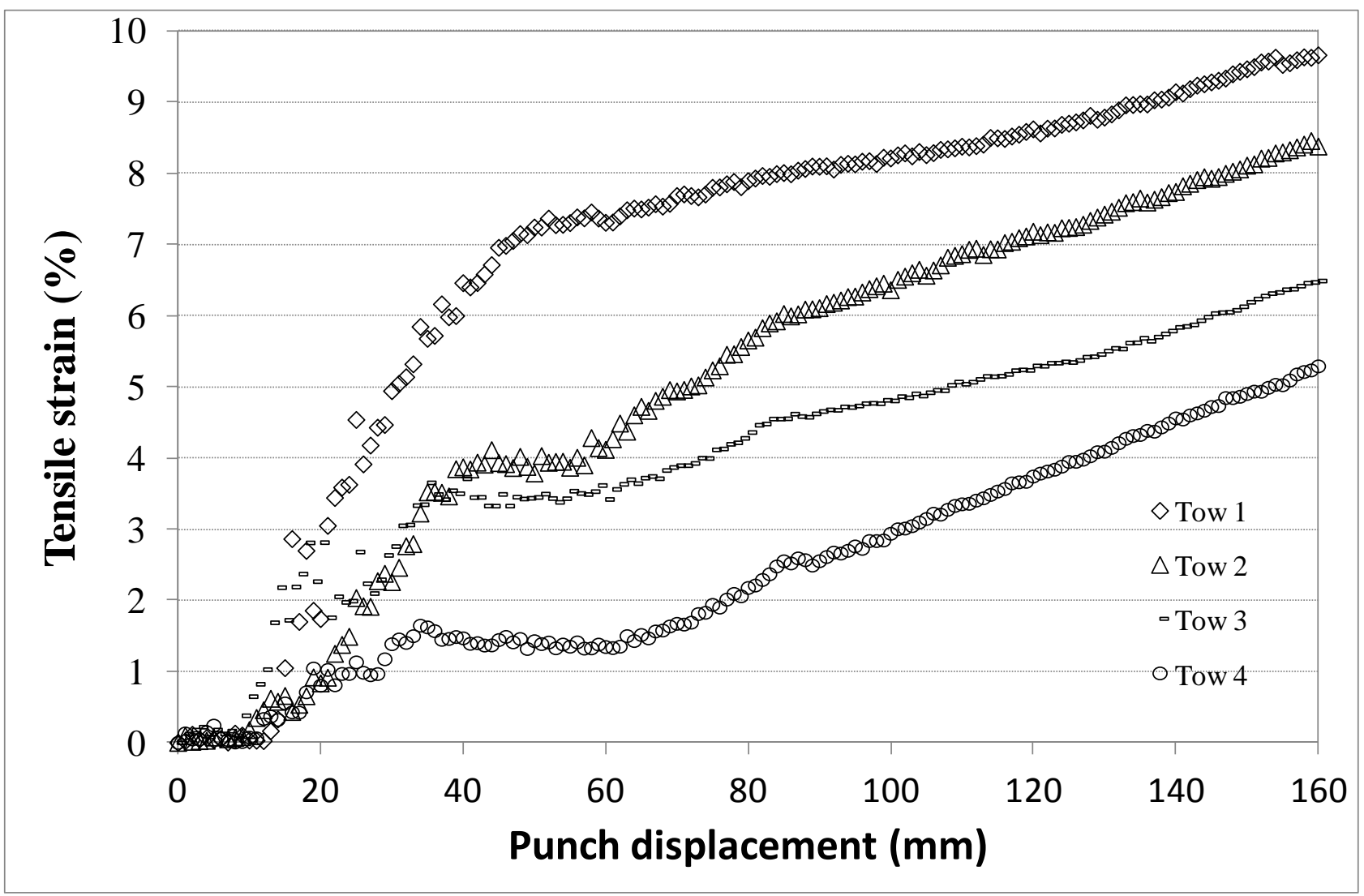

Figure 7: Strain evolution in vertical tows during the sheet forming process. Orientation $0^{\circ}$

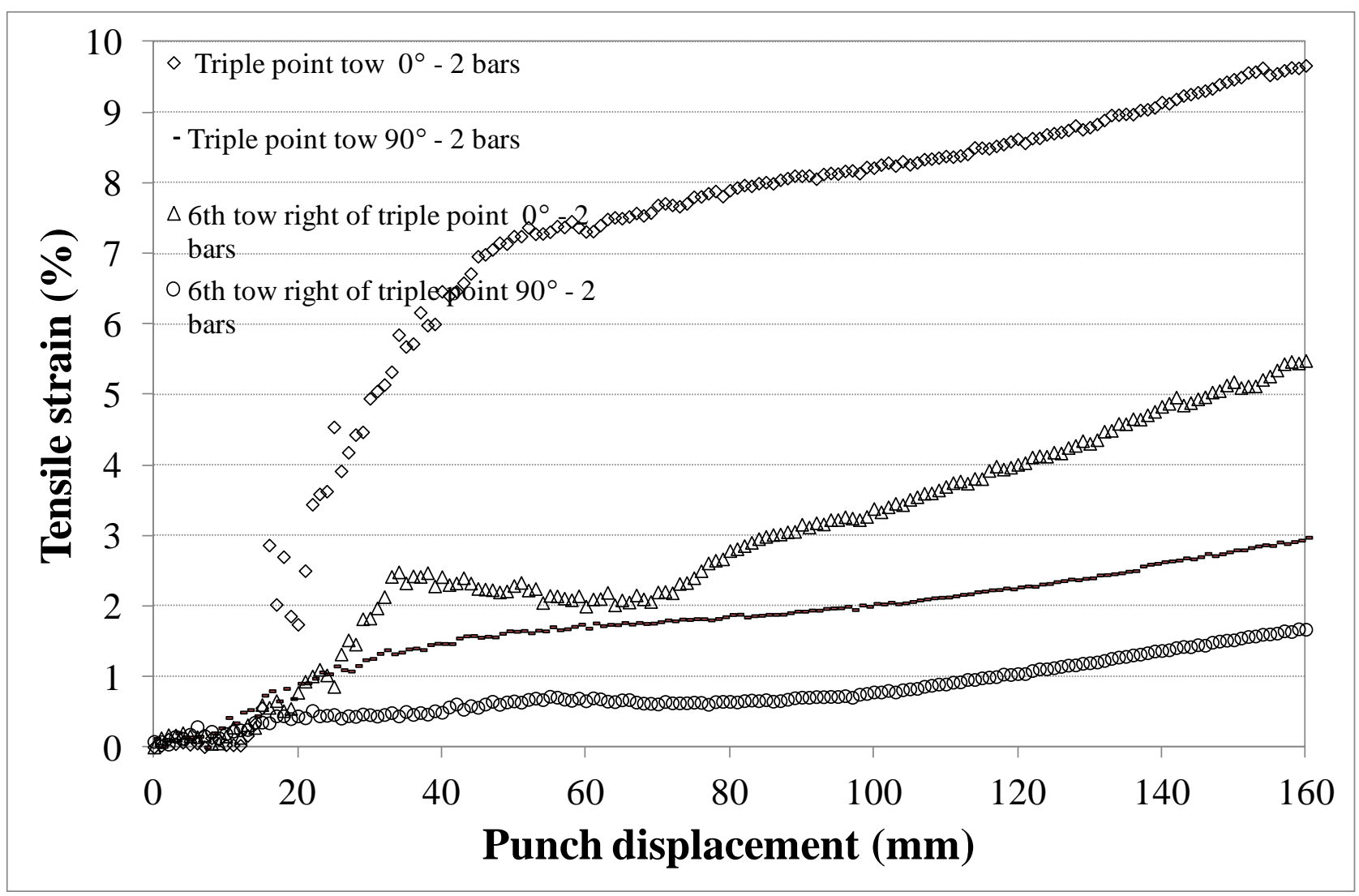

Figure 8: Influence of the fabric orientation on the tensile strain of two selected tows 


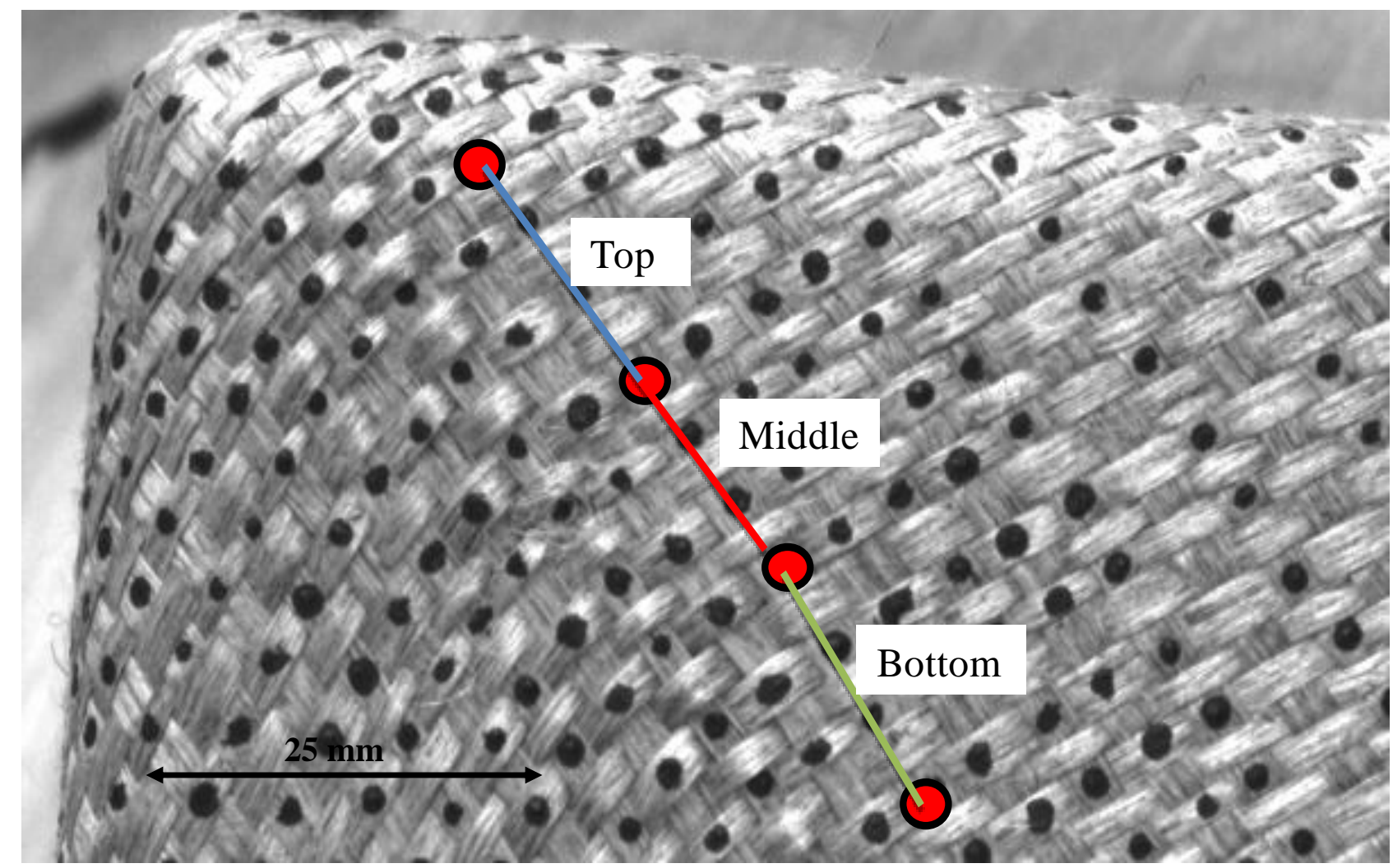

Figure 9: Position of the strain measurement on a single selected tow

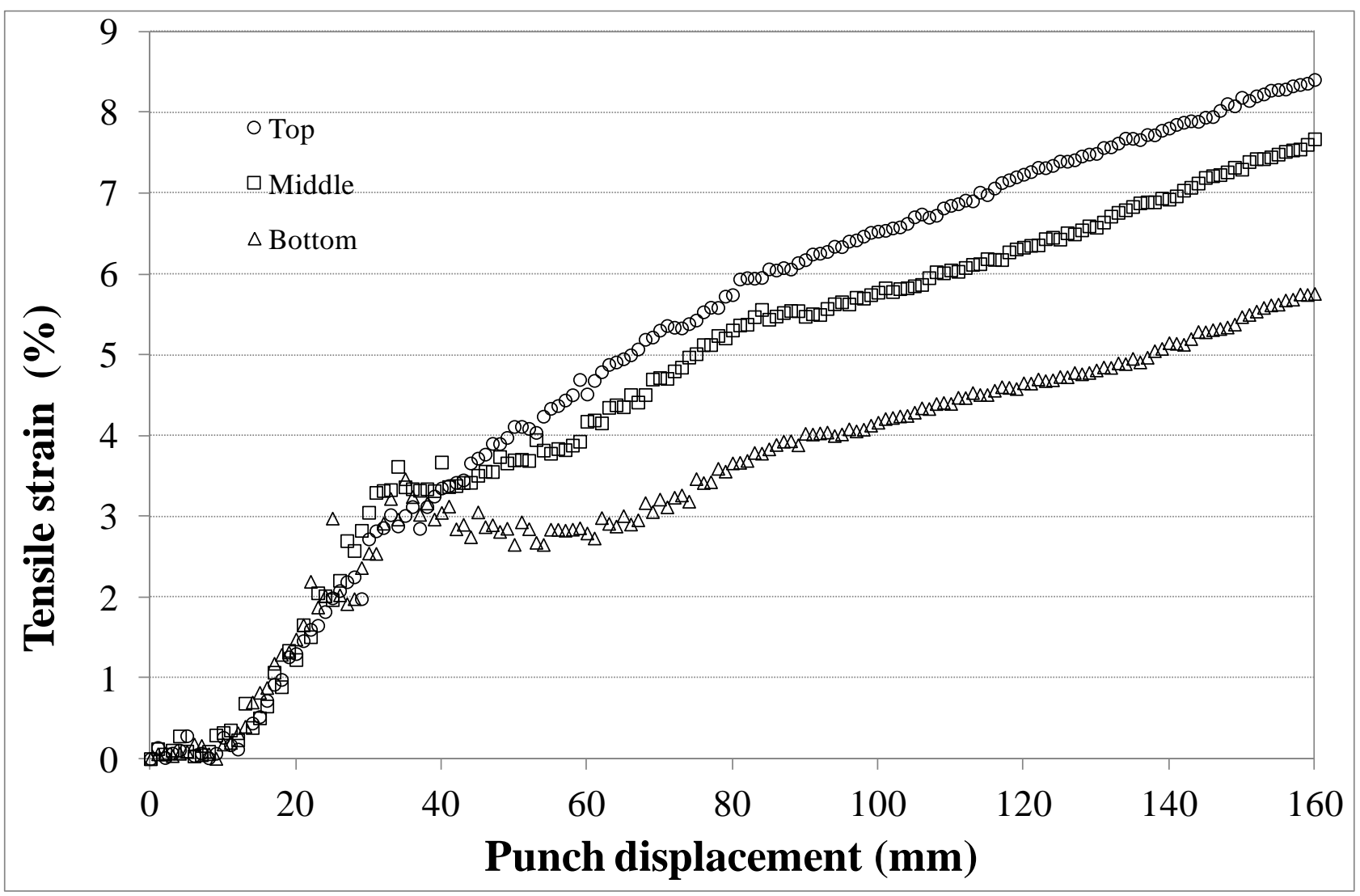

Figure 10: Influence of the measurement position on the tensile strain of one single selected tow with orientation $0^{\circ}$ 


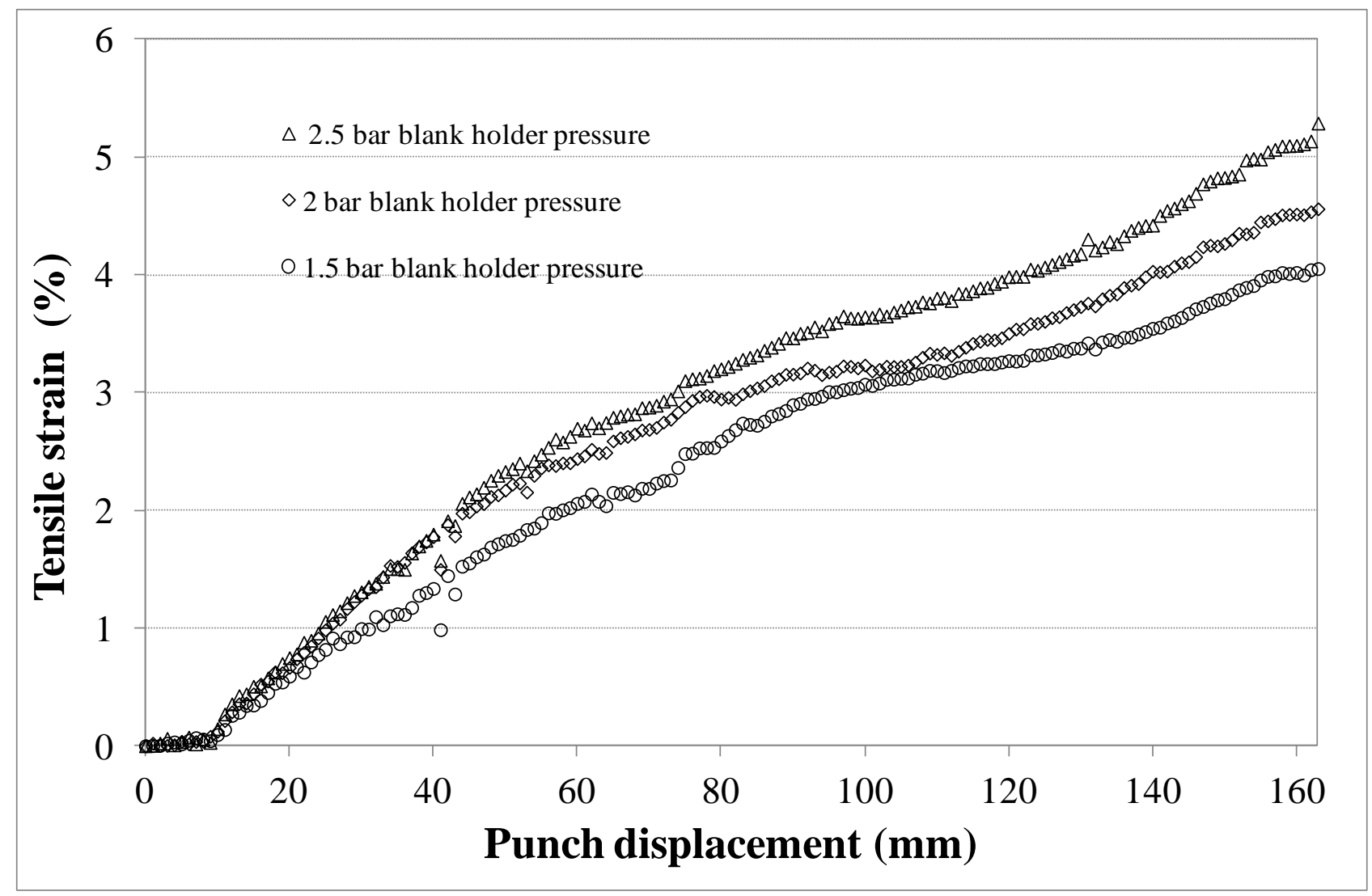

Figure 11: Influence of the blank holder pressure on the tensile strain of a selected tow. $8^{\text {th }}$ tow, Orientation $0^{\circ}$

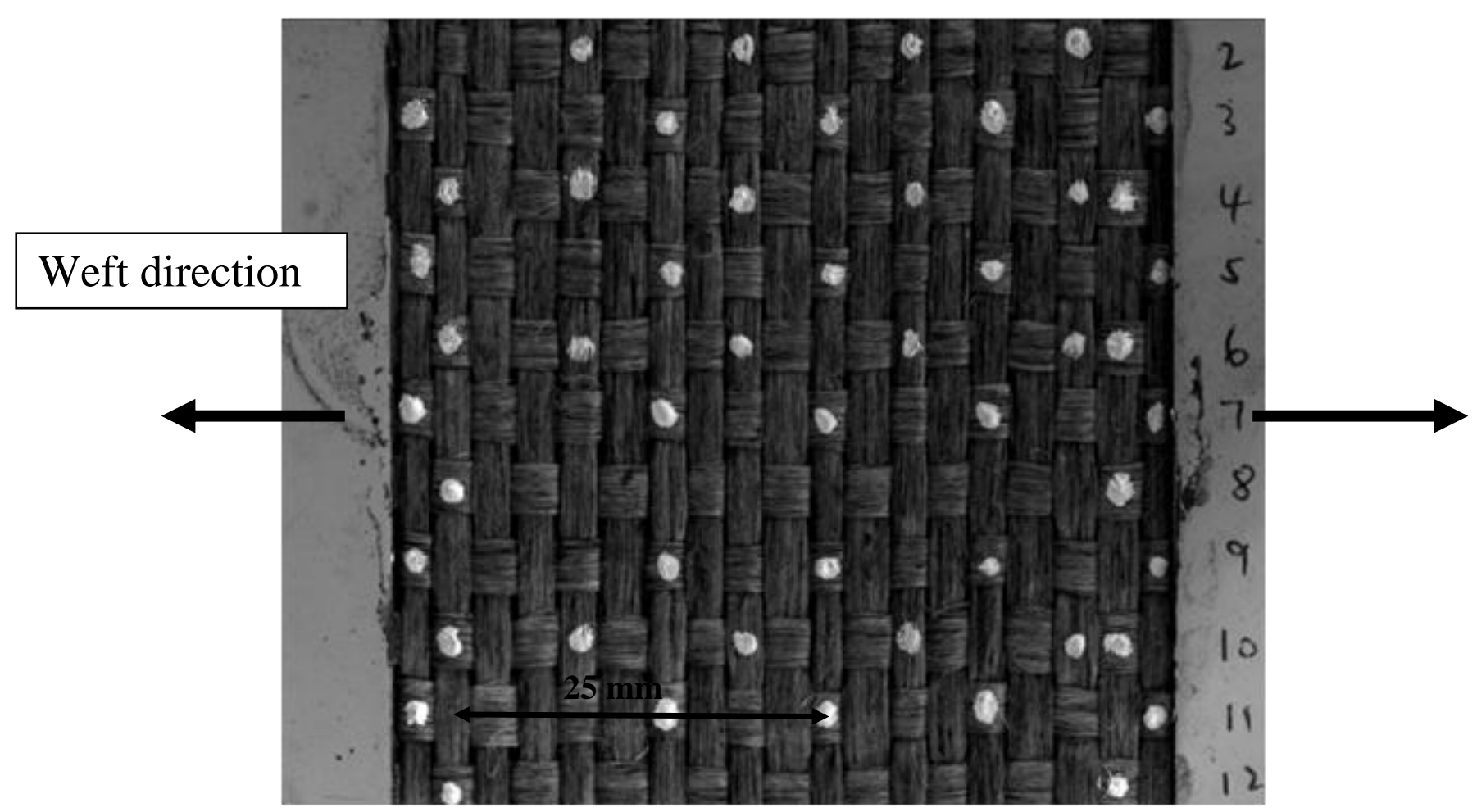

Figure 12: Uniaxial tensile test sample. Weft direction. 


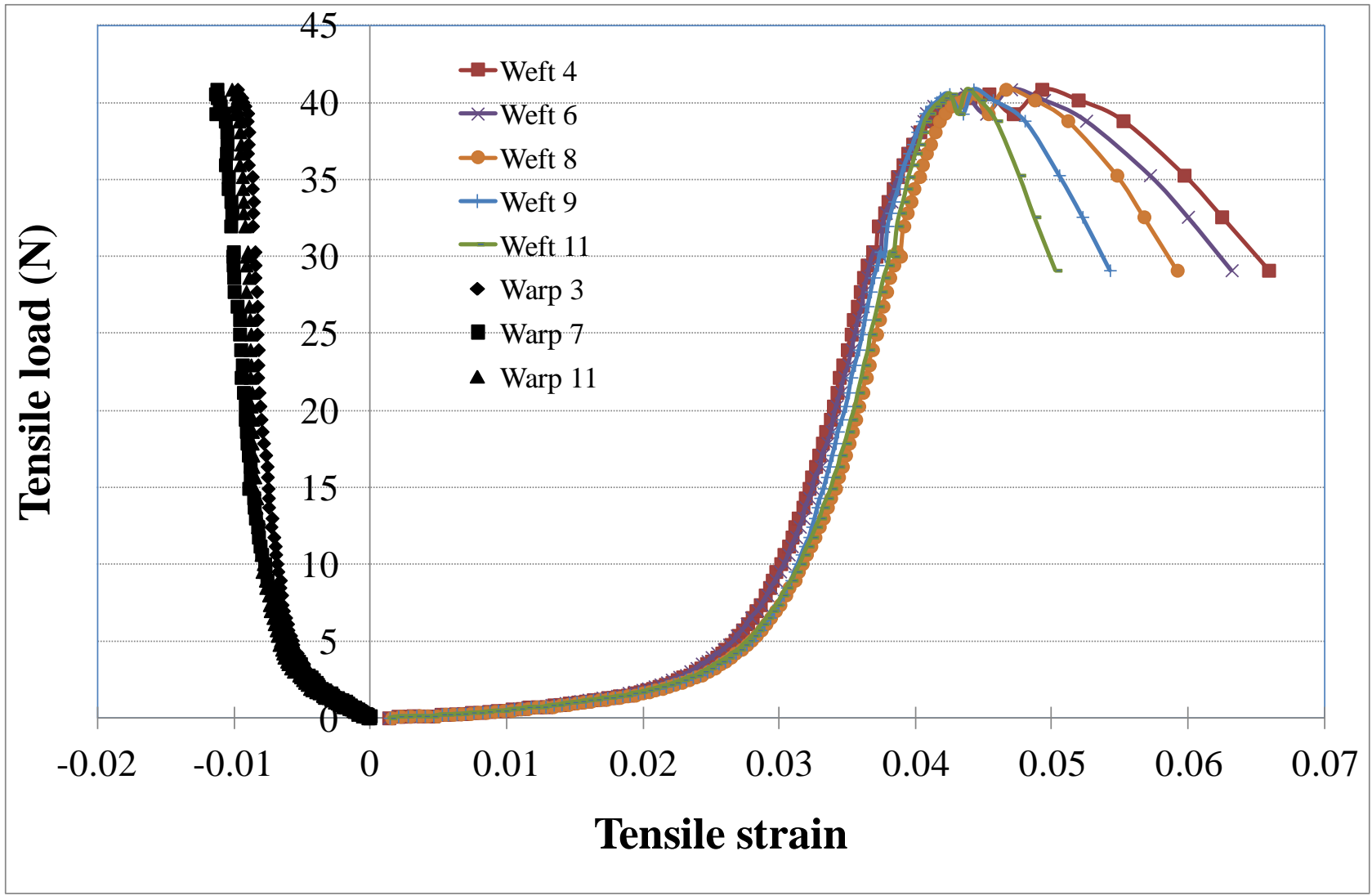

Figure 13: Uniaxial tensile behaviour of the weft tows. Load applied in the weft direction of the woven fabric

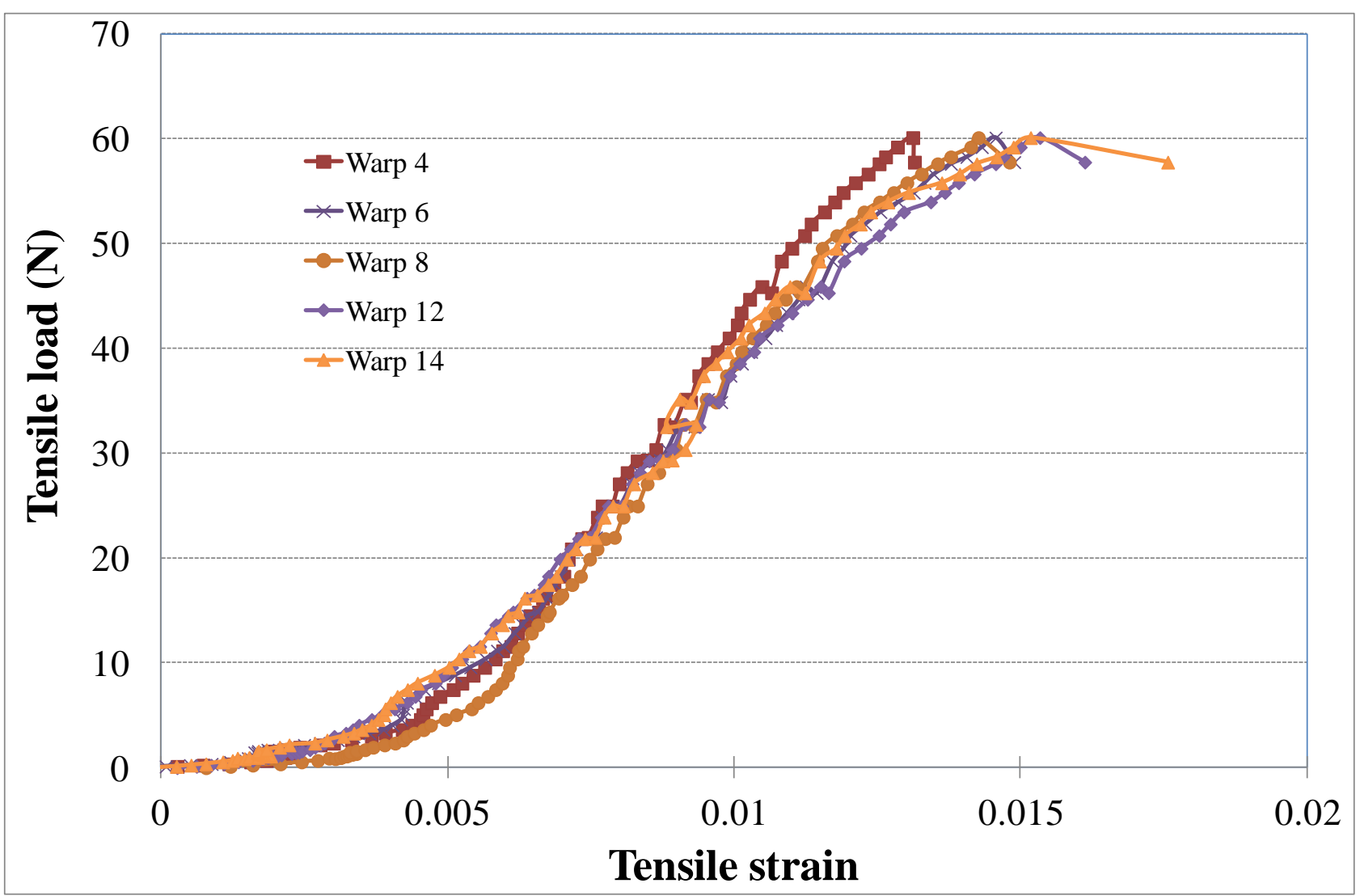

Figure 14: Uniaxial tensile behaviour of the warp tows. Load applied in the warp direction of the woven fabric 


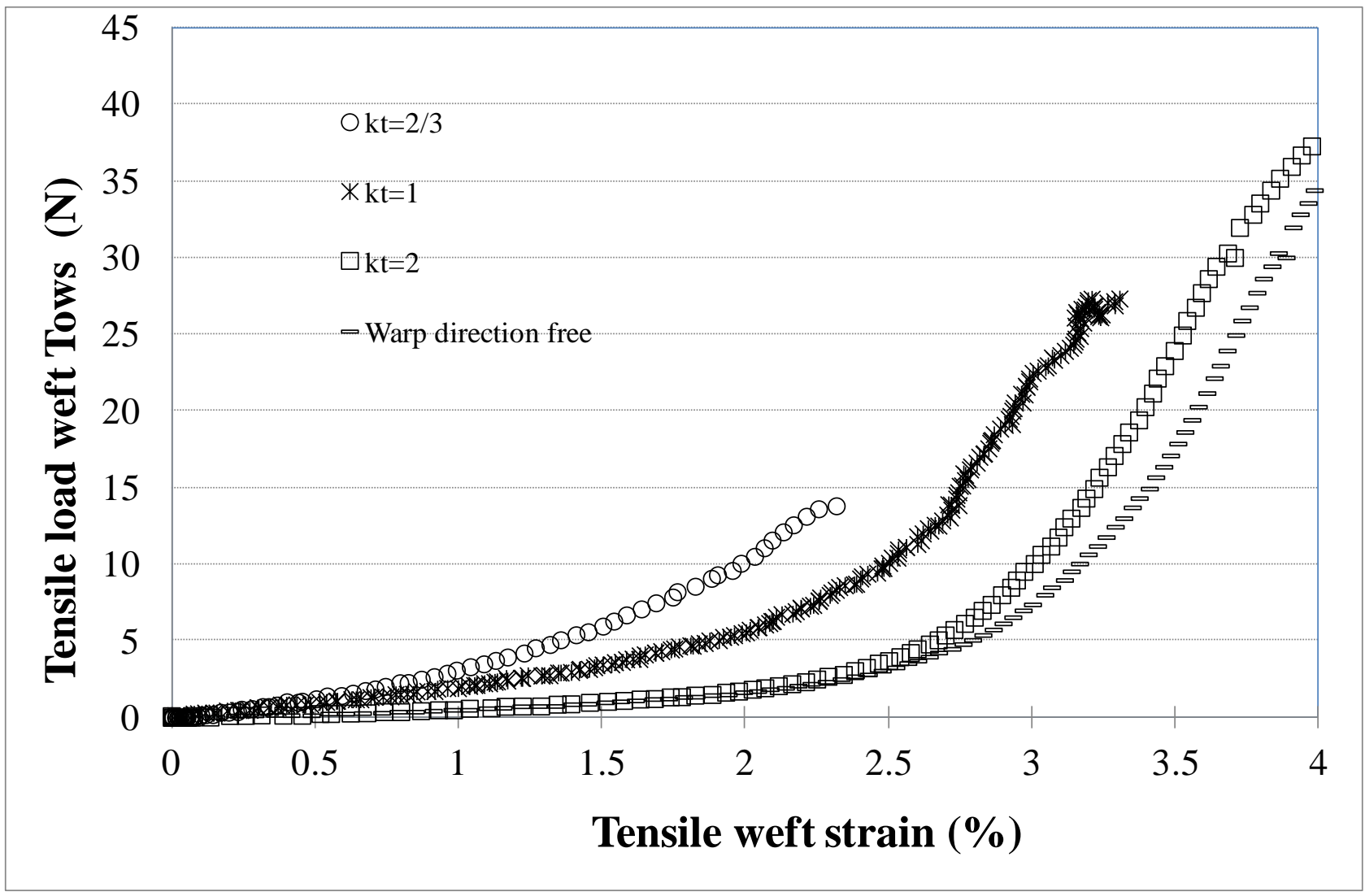

Figure 15: Tensile behaviour of the weft tows during a biaxial test

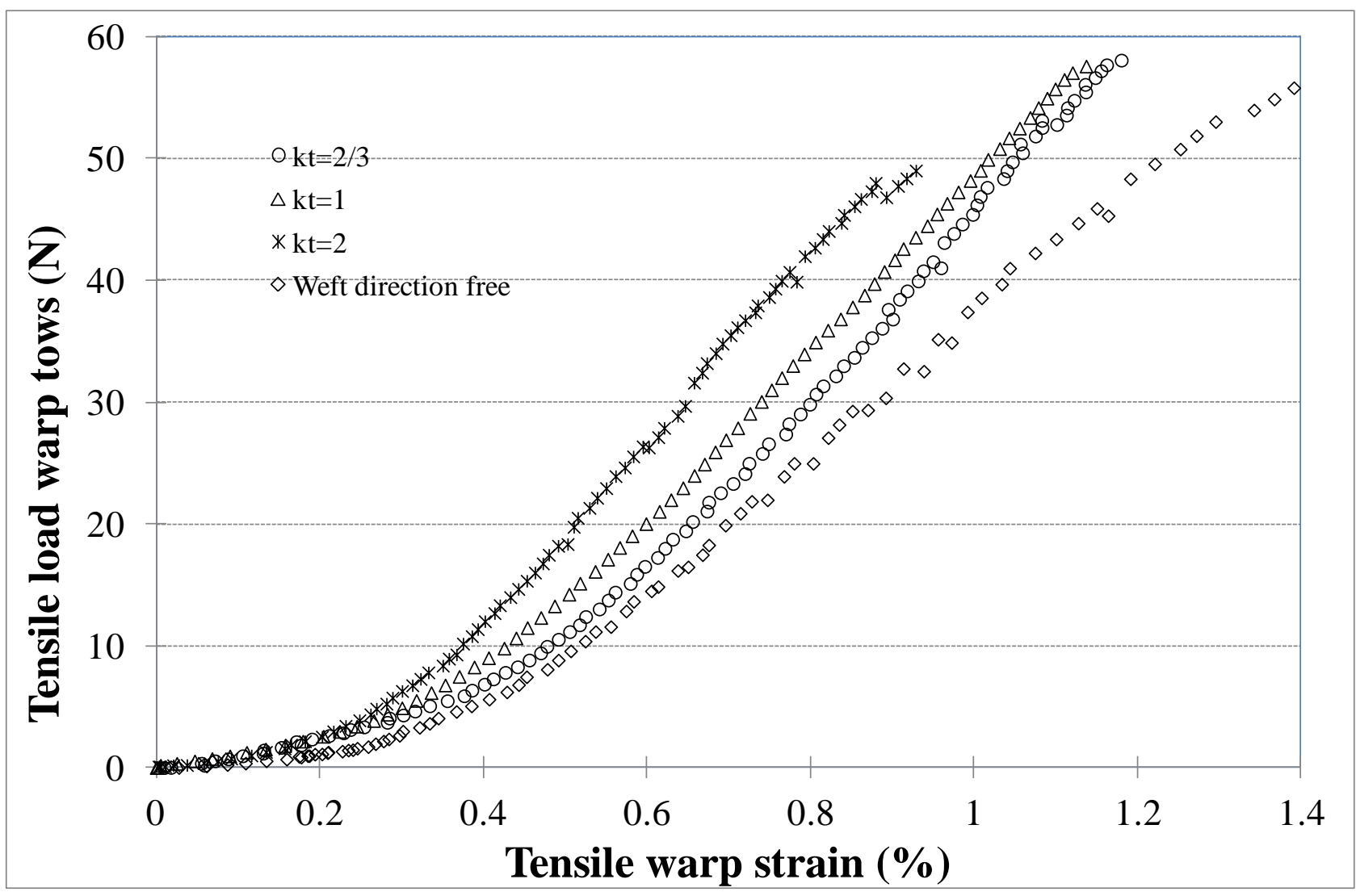

Figure 16: Tensile behaviour of the warp tows during a biaxial test 